\title{
Pengaruh Metode Latihan Drill dan Koordinasi terhadap Ketepatan Servis Tenis Meja
}

\author{
M. Mu'ammar \\ IKIP PGRI Kalimantan Timur. Jalan H. Suwandi, Gn. Kelua, Kota Samarinda, 75243, Indonesia \\ Email: amarmuammar76@yahoo.com \\ Received: 31 January 2017; Revised:17 April 2017; Accepted: 21 April 2017
}

\begin{abstract}
Abstrak
Penelitian ini bertujuan untuk mengetahui: (1) perbedaan pengaruh metode latihan drill arah sasaran konstan dan drill arah sasaran berubah-ubah terhadap ketepatan servis backspin tenis meja atlet pemula, (2) perbedaan keterampilan sevis backspin tenis meja antara siswa yang mempunyai koordinasi tinggi dan rendah, dan (3) interaksi antara metode latihan drill arah sasaran konstan dan drill arah sasaran berubahubah dan koordinasi terhadap ketepatan servis tenis meja atlet pemula. Penelitiaan ini merupakan penelitian ekperimen dengan rancangan faktorial $2 \times 2$. Sampel penelitian ini 28 atlet yang diambil dengan teknik rondom sampling. Teknik analisis data yang digunakan adalah analisis varian (ANAVA). Hasil penelitian ini menunjukkan bahwa: (1) ada perbedaan pengaruh yang signifikan antara latihan metode drill arah sasaran konstan dan drill arah sasaran berubah-ubah terhadap ketepatan servis backspin tenis meja atlet pemula, (2) ada perbedaan yang signifikan hasil keterampilan servis backspin tenis meja antara siswa yang mempunyai koordinasi tinggi dan rendah, dan (3) ada interaksi antara metode latihan drill arah sasaran konstan dan drill arah sasaran berubah-ubah dan koordinasi terhadap ketepatan sevis tenis meja atlet pemula. Kelompok atlet tenis meja yang memiliki koordinasi tinggi lebih tepat jika dilatih dengan drill arah sasaran berubah-ubah, sedangkan kelompok atlet tenis meja yang memiliki koordinasi rendah lebih baik jika dilatih dengan metode drill arah sasaran konstan.
\end{abstract}

Kata Kunci: metode latihan drill, koordinasi, atlet pemula tenis meja, ketepatan servis backspin

\section{The Effects of Drill Training Method and Coordination on the Accuracy of Table Tennis Service}

\begin{abstract}
This study aims to investigate: (1) the difference of the effect of drill training method for a constant target and that for a variable target on the accuracy of table tennis backspin service among novice athletes, (2) the difference of table tennis backspin service skill between students with high coordination and those with low coordination, and (3) the interaction of drill training method for a constant target and that for a variable target and coordination on the accuracy of table tennis service among novice table tennis athletes. This was an experimental study employing a $2 \times 2$ factorial design. The research sample consisted of 28 athletes, selected by means of sample technique. The data were collected through test. The test were used to assess the service skills before and after treatment. The data were analyzed using the twoway analysis of variance (ANOVA). The results of the study were as follows: (1) there is a significant difference in the effect of drill training method for a constant target and that for a variable target on the accuracy of table tennis backspin service among novice table tennis athletes, (2) there is a significant difference in table tennis backspin service skill between the students with high coordination and those with low coordination, and (3) there is an interaction of drill training method for a constant target and that for a variable target and coordination on the accuracy of the table tennis service among novice table tennis athletes. The group of table tennis athletes with high coordination has higher accuracy when they are trained through the drill method for a variable target, while those with low coordination are better when they are trained through the drill method for a constant target.
\end{abstract}

Keywords: drill training method, coordination, novice table tennis athletes, accuracy, backspin service

How to Cite: Mu'ammar, M. (2017). Pengaruh metode latihan drill dan koordinasi terhadap ketepatan servis tenis meja. Jurnal Keolahragaan, 5(1), 63-70. doi:http://dx.doi.org/10.21831/jk.v5i1.12805

Permalink/DOI: http://dx.doi.org/10.21831/jk.v5i1.12805 


\section{PENDAHULUAN}

Menurut Katsikadelis, Pilianidis, \& Mantzoura (2013, p. 1), the serve in table tennis is a unique which closely realeted to the player's strategy. Artinya, dalam permainan tenis meja servis adalah sesuatu yang unik yang berkaitan erat dengan strategi seorang pemain. Menurut The International Table Tennis Federation (2016, pp. 26-27) ketepatan servis sangat menguntungkan bagi pemain dalam memenangkan pertandingan.

Begitu pula menurut Tomoliyus (2014, p. 1) servis merupakan tindakan pertama dalam permainan tenis meja dan juga sebagai serangan pertama kali bagi pemain yang melakukan service yang sukar atau sulit diterima oleh pihak lawan dapatlah dipakai suatu senjata untuk mengadakan suatu serangan. Oleh karena itu, servis merupakan suatu pukulan yang penting digunakan untuk serangan pertama dalam menyajikan sebuah permainan. Jadi latihan servis sangat penting dalam pencapaian atlet tenis meja dalam memenangkan pertandingan. Tanpa mengesampingkan teknik yang lain, pelaksanaan latihan servis perlu dilakukan dengan baik.

Dalam melakukan servis tenis meja untuk menghasilkan spin yang kuat, seorang atlet tidak hanya memukul dengan sekuat tenaga, tetapi harus dengan kontrol dan feeling yang baik serta mempunyai koordinasi yang baik pula. Oleh karena itu dalam memantulkan di bidang meja sendiri dan memantulkan ke meja lawan, diperlukan kemampuan koordinasi yang baik dalam melakukan pukulan dengan sasaran yang diinginkan.

Selain penguasaan teknik yang baik dalam permainan tenis meja, ketepatan sasaran merupakan salah satu faktor yang terpenting dalam bermain tenis meja. Ketepatan sasaran yang dimaksud adalah ketepatan penempatan pukulan pada sasaran yang telah ditetapkan. Agar mendapatkan skor, seorang pemain berusaha menempatan bola tepat pada sasaran dengan laju bola cepat yang jauh dari jangkauan lawan, sehingga sulit mengembalikan bola. Salah satu faktor yang berperan penting dalam ketepatan servis ialah koordinasi. Apabila atlet memiliki koordinasi yang kurang baik, seorang atlet tersebut kurang mampu mengaplikasikan teknik servis dalam pertandingan.

Koordinasi didefinisikan sebagai hubungan yang harmonis dari hubungan di antara kelompok-kelompok otot selama melakukan kerja, yang ditunjukkan dengan berbagai tingkat keterampilan (Ismaryati, 2011, p. 54). Untuk mencapai servis yang tepat dan sulit diterima lawan diperlukan metode yang tepat. Pengunaan metode yang tepat bagi atlet pemula tenis meja dalam melakukan servis akan mempermudah proses latihan untuk mencapai tujuan yang diharapkan.

Salah satu metode latihan yang digunakan dalam meningkatkan servis tenis meja adalah metode drill. Metode drill tersebut akan dibedakan menjadi dua jenis latihan yaitu drill arah konstan dan drill arah sasaran berubahubah. Kedua metode tersebut masing-masing memiliki karakteristik yang berbeda yang belum diketahui pengaruh dalam meningkatkan ketepatan servis tenis meja bagi altet pemula Sleman di PTM Punglor.

Penelitian ini bertujuan untuk mengetahui: (1) perbedaan pengaruh metode latihan drill arah sasaran konstan dan drill arah sasaran berubah-ubah terhadap ketepatan servis backspin tenis meja atlet pemula, (2) perbedaan keterampilan sevis backspin tenis meja antara siswa yang mempunyai koordinasi tinggi dan rendah, dan (3) interaksi antara metode latihan drill arah sasaran konstan dan drill arah sasaran berubah-ubah dan koordinasi terhadap ketepatan servis tenis meja atlet pemula.

\section{METODE}

Penelitian ini merupakan penelitian eksperimen faktorial desain. Eksperimen faktorial merupakan modifikasi dari desain true experimental, dengan memperhatikan kemungkinan adanya variabel moderator yang memengaruhi variabel independent terhadap variabel dependent (Sugiyono, 2010, p. 76). Metode penelitian yang digunakan dalam penelitian ini adalah rancangan faktorial $2 \times 2$, yaitu tiap-tiap faktor terdiri atas dua buah taraf, dengan membandingkan hasil dari tes akhir (posttest). Menurut Sudjana (2002, p. 148) eksperimen faktorial adalah eksperimen yang hampir atau semua taraf sebuah faktor dikombinasikan atau disilangkan dengan semua taraf tiap faktor lainnya yang ada dalam eksperimen.

Pada penelitian eksperimen ini desain faktorial penelitian dengan dua faktor yang tiap faktorial terdiri atas dua taraf. Dalam penelitian ini variabel bebas (independent) manipulatif adalah metode drill sasaran konstan dan metode drill sasaran yang berubah-ubah. Variabel bebas atributif adalah koordinasi. Kemudian variabel terikat (dependent) adalah ketepatan servis backspin permaianan tenis meja. Rancangan 
penelitian yang dimaksud dapat dilihat pada Tabel 1.

Tabel 1. Rancangan Penelitian Faktorial 2x2

\begin{tabular}{ccc}
\hline Koodinasi (B) & \multicolumn{2}{c}{ Metode $\operatorname{drill}(\mathbf{A})$} \\
\cline { 2 - 3 } & $\begin{array}{c}\text { Sasaran } \\
\text { Konstan } \mathrm{A}_{\mathbf{1}}\end{array}$ & $\begin{array}{c}\text { Berubah- } \\
\text { ubah A }\end{array}$ \\
\hline $\begin{array}{c}\text { Koordinasi } \\
\text { Tinggi } \mathrm{B}_{1}\end{array}$ & $\mathrm{~A}_{1} \mathrm{~B}_{1}$ & $\mathrm{~A}_{2} \mathrm{~B}_{1}$ \\
$\begin{array}{c}\text { Koordinasi } \\
\text { Rendah } \mathrm{B}_{2}\end{array}$ & $\mathrm{~A}_{1} \mathrm{~B}_{2}$ & $\mathrm{~A}_{2} \mathrm{~B}_{2}$ \\
\hline
\end{tabular}

Metode drill sasaran konstan $\left(\mathrm{A}_{1}\right) \mathrm{A}_{1} \mathrm{~B}_{1} \mathrm{~A}_{1} \mathrm{~B}_{2}$

Metode drill sasaran berubah-ubah $\left(\mathrm{A}_{2}\right) \mathrm{A}_{2} \mathrm{~B}_{1}$

$\mathrm{A}_{2} \mathrm{~B}_{2}$

Keterangan:

$\mathrm{A}_{1} \mathrm{~B}_{1}$ : Kelompok atlet pemula yang dilatih menggunakan metode drill sasaran konstan yang memiliki koordinasi tinggi.

$\mathrm{A}_{2} \mathrm{~B}_{1}$ : Kelompok atlet pemula yang dilatih metode drill sasaran berubah-ubah yang memiliki koordinasi tinggi.

$\mathrm{A}_{1} \mathrm{~B}_{2}$ : Kelompok atlet pemula dilatih menggunakan motode drill sasaran konstan yang memiliki koordinasi rendah

$\mathrm{A}_{2} \mathrm{~B}_{2}$ : kelompok atlet pemula dilatih menggunakan metode drill sasaran berubahubah yang memiliki koordinasi rendah.

\section{Populasi dan Sampel Penelitian}

Populasi dalam penelitian ini adalah atlet pemula tenis meja di Kabupaten Sleman sebanyak 48 orang. Jumlah sampel 30 atlet pemula diambil dengan cara random sampling. Pembagian kelompok dengan cara ranking ditentukan $27 \%$ kelompok atas dan $27 \%$ kelompok bawah dari hasil tes (Miller, 2013, p. 68). Dengan demikian pengelompokan sampel diambil dari atlet pemula yang memiliki motivasi tinggi sebanyak $27 \%$ dan atlet yang memiliki motivasi rendah sebanyak $27 \%$ dari data yang telah diranking.

Tabel 2. Pengelompokan Sampel Berdasarkan Perlakuan

\begin{tabular}{ccc}
\hline \multirow{2}{*}{$\begin{array}{c}\text { Koodinasi } \\
(\mathbf{B})\end{array}$} & \multicolumn{2}{c}{ Metode $\operatorname{Drill}(\mathbf{A})$} \\
\cline { 2 - 3 } & $\begin{array}{c}\text { Sasaran Konstan } \\
\mathbf{A}_{\mathbf{1}}\end{array}$ & $\begin{array}{c}\text { Berubah-ubah } \\
\mathbf{A}_{\mathbf{2}}\end{array}$ \\
\hline $\begin{array}{c}\text { Koordinasi } \\
\text { tinggi } \mathrm{B}_{1}\end{array}$ & 7 atlet & 7 atlet \\
$\begin{array}{c}\text { Koordinasi } \\
\text { rendah } \mathrm{B}_{2}\end{array}$ & 7 atlet & 7 atlet \\
\hline
\end{tabular}

Berdasarkan hal tersebut didapatkan 14 atlet pemula yang memiliki koordinasi tinggi dan 14 atlet pemula yang memiliki koordinasi rendah. Untuk jelasnya komposisi subjek seba- gai sampel penelitian berdasarkan kelompok koordinasi dan jenis perlakuan dapat disajikan pada Tabel 2.

\section{Teknik Analisis Data}

Teknik analisis data yang digunakan yaitu analisis varian (Anava) tiga jalur pada taraf signifikansi $\alpha=0,05$. Untuk memenuhi asumsi Anava, dilakukan uji normalitas dengan Kolmogorov Smirnow dan homogenitas dengan uji Levene Test. Untuk menguji hipotesis dilakukan dengan menggunakan Anava dua jalur dan apabila terbukti terdapat interaksi. Akan dilakukan uji lanjutan yaitu uji Tukey yaitu dengan menggunakan program software SPSS version 20.0 for windows dengan taraf signifikansi $5 \%$ atau 0,05 .

\section{HASIL DAN PEMBAHASAN}

Hasil uji prasyarat yaitu uji normalitas dan homogenitas data dihasilkan bahwa data penelitian normal dan homogen. Berikut hasil penghitungan analisis varian (Anava) disajikan pada Tabel 3.

Tabel 3. Rangkuman Hasil Analisis Varian (Anava) Two-Way

\begin{tabular}{ccccc}
\hline Source & Df & Mean & P & Ket \\
\hline Metode Latihan & 1 & 72,321 &, 045 & Sig. \\
Koordinasi & 1 & 71,003 &, 000 & Sig. \\
MetodeKoordinasi & 1 & 132,89 &, 008 & Sig. \\
\hline
\end{tabular}

Berdasarkan hasil Tabel 3, penghitungan menunjukkan perbedaan pengaruh latihan antara metode drill arah sasaran konstan dan metode drill arah sasaran berubah-ubah. Hal ini dibuktikan dari nilai $\mathrm{p}$ sebesar $0,045<0,05$. Artinya, terdapat perbedaan pengaruh antara metode drill arah sasaran konstan dan drill arah sasaran berubah-ubah terhadap ketepatan servis backspin tenis meja atlet pemula. Perbedaan pengaruh latihan bagi atlet yang memiliki koordinasi tinggi dan rendah terhadap ketepatan servis tenis meja.

Berdasarkan hasil penghitungan diketahui terdapat perbedaan pengaruh antara koordinasi tinggi dan koordinasi rendah terhadap ketepatan servis backspin tenis meja atlet pemula. Hal ini terbukti dari nilai $\mathrm{F}$ hitung tes akhir sebesar 4.395 pada taraf signifikansi $0.000<0.05$.

\section{Interaksi antara Metode Latihan Drill dan Koordinasi terhadap Ketepatan Servis Tenis Meja}

Hasil penghitungan diketahui ada interaksi antara metode latihan drill (konstan dan 
berubah-ubah) dan koordinasi terhadap ketepatan servis backspin atlet pemula tenis meja. Terdapat interaksi antara metode latihan drill arah sasaran konstan dan drill arah sasaran berubah-ubah dan koordinasi terhadap ketepatan servis tenis meja atlet pemula. Hal ini dibuktikan dari nilai p sebesar 0,08<0,05.

Selanjutnya, setelah diketahui interaksi dari kedua metode, perlu dilakukan uji lanjut dengan menggunakan uji Tukey untuk mengetahui pengaruh antarkelompok perlakuan. Berikut hasil uji lanjut dapat dilihat pada Gambar 1.

Tabel 3. Analisis Uji Lanjut Tukey

\begin{tabular}{llrrc}
\hline (I) co & $(J)$ co Mean Difference (I-J) & $\begin{array}{c}\text { Std. } \\
\text { Error }\end{array}$ & Sig. \\
\hline & $A_{1} B_{2}$ & 5,00000 & 1,90506 &, 066 \\
$A_{1} B_{1}$ & $A_{2} B_{1}$ & $-9,00000^{*}$ & 1,90506 &, 000 \\
& $A_{2} B_{2}$ & $6,14286^{*}$ & 1,90506 &, 018 \\
\hline & $A_{1} B_{1}$ & $-5,00000$ & 1,90506 &, 066 \\
$A_{1} B_{2}$ & $A_{2} B_{1}$ & $-14,00000^{*}$ & 1,90506 &, 000 \\
& $A_{2} B_{2}$ & 1,14286 & 1,90506 &, 931 \\
\hline & $A_{1} B_{1}$ & $9,00000^{*}$ & 1,90506 &, 000 \\
$A_{2} B_{1}$ & $A_{1} B_{2}$ & $14,00000^{*}$ & 1,90506 &, 000 \\
& $A_{2} B_{2}$ & $15,14286^{*}$ & 1,90506 &, 000 \\
\hline & $A_{1} B_{1}$ & $-6,14286$ & 1,90506 &, 018 \\
$A_{2} B_{2}$ & $A_{1} B_{2}$ & $-1,14286$ & 1,90506 &, 931 \\
& $A_{2} B_{1}$ & $-15,14286^{*}$ & 1,90506 &, 000 \\
\hline & $B_{1}$ & &
\end{tabular}

Berdasarkan Tabel 3 hasil perhitungan uji

Tukey pada tanda asterisk (*) menunjukkan bahwa pasangan kelompok perlakuan yang terdapat pengaruh secara nyata (signifikan) dapat dilihat Jika $\alpha=0,05$ jika $[\alpha=0,05 \geq$ sig $]$ atau F hitung < F tabel, Ho diterima, (2) Jika $[\alpha=0,05 \leq s i g]$, atau $\mathrm{F}$ hitung $>\mathrm{F}$ tabel, $\mathrm{H}_{0}$ ditolak. Adapun pasangan kelompok adalah: (1) pasangan antara $A_{1} B_{1}$ dengan $A_{2} B_{1}$, (2) pasangan antara $A_{1} B_{1}$ dengan $A_{2} B_{2}$, (3) $A_{1} B_{2}$ dengan $A_{2} B_{1}$, (4) pasangan antara $A_{2} B_{1}$ dengan $A_{1} B_{1}$. (5) $A_{2} B_{1}$ dengan $A_{1} B_{2}$, (6) $A_{2} B_{1}$ dengan $A_{2} B_{2}$, (7) $A_{2} B_{2}$ dengan $A_{1} B_{1}$, (8) $A_{2} B_{2}$ dengan $A_{2} B_{1}$.

Jadi dapat disimpulkam bahwa: (1) terdapat perbedaan pengaruh yang signifikan antara drill konstan koordinasi tinggi dipasangkan dengan drill berubah-ubah koordinasi tinggi, (2) terdapat perbedaan pengaruh yang signifikan drill berubah-ubah koordinasi tinggi dipasangkan dengan drill berubah-ubah koordinasi rendah, (3) terdapat perbedaan pengaruh yang signifikan drill konstan koordinasi rendah dipasangkan dengan drill berubah-ubah koordinasi tinggi, (4) terdapat perbedaan pengaruh yang signifikan drill berubah-ubah tinggi dipasangkan drill konstan koordinasi tinggi, (5) terdapat perbedaan pengaruh yang signifikan drill berubah- ubah koordinasi tinggi dipasangkan drill konstan koordinasi rendah, (6) terdapat perbedaan pengaruh yang signifikan drill berubah-ubah tinggi dipasangkan drill konstan koordinasi tinggi, (7) terdapat perbedaan pengaruh yang signifikan drill berubah-ubah koordinasi rendah dipasangkan drill berubah-ubah koordinasi tnggi.

Pasangan-pasangan lainnya dinyatakan tidak memiliki perbedaan pengaruh adalah: (1) $A_{1} B_{1}$ dengan $A_{1} B_{2}$, (2) $A_{1} B_{2}$ dengan $A_{2} B_{2}$. Jadi dapat disimpulkan: (1) tidak terdapat perbedaan pengaruh yang signifikan drill konstan koordinasi tinggi dipasangkan drill konstan koordinasi tinggi, (2) tidak terdapat perbedaan pengaruh yang signifikan drill konstan koordinasi rendah dipasangkan drill berubah-ubah koordinasi rendah.

Berdasarkan Gambar 1, dapat diketahui bahwa bentuk garis perubahan besarnya nilainya adalah tidak sejajar dan bersilangan. Garis perubahan peningkatan hasil ketepatan antar kelompok memiliki suatu titik pertemuan atau persilangan, antara metode drill sasaran (konstan dan berubah-ubah) untuk meningkatkan hasil penempatan servis backspin. Ini berarti bahwa terdapat interaksi yang signifikan di antara keduanya.

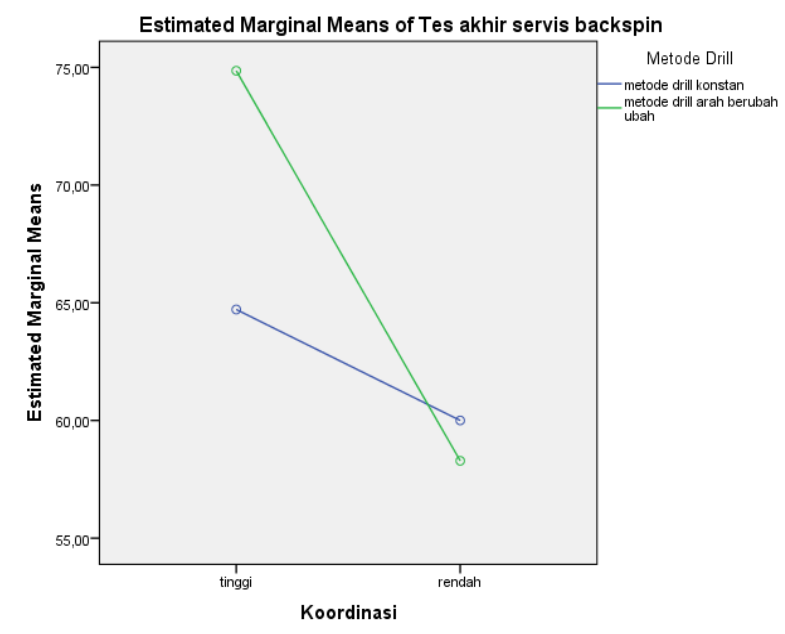

Gambar 1. Plot Interaksi

\section{Pembahasan}

Perbedaan Pengaruh Metode Latihan antara Drill Arah Sasaran Konstan dan drill Arah Sasaran Berubah-Ubah terhadap Hasil Ketepatan Servis Backspin

Metode drill sasaran konstan adalah metode latihan yang pelaksanaannya melakukan gerakan servis dengan sasaran yang konstan dan terus menerus tanpa henti pada tiap sesi latihanya sampai batas waktu latihan ditetapkan. 
Metode drill sasaran konstan merupakan suatu metode yang yang bertujuan untuk meningkatkan teknik keterampilan. Sesuai dengan pendapat Edwards (2011, p. 409), terdapat pengulangan keterampilan yang sama selama beberapa percobaan memungkinkan peserta didik untuk melakukan menyesuaikan kinerja dalam memori atau ingatan kerja. Pengulangan gerakan ini dimaksudkan agar terjadi otomatisasi gerakan sehingga siswa mencapai kemahiran, sesuai dengan hukum latihan.

Selain itu metode drill konstan termasuk dalam pembelajaran motorik yang bersifat tertutup artinya seseorang dalam melakan sesuatu dengan lingkungan yang yang bersifat tetap, sehingga seorang atlet dapat mengendalikannya dan terencana sebelumnya. Mudah dikendalikan dan direncanakan oleh atlet itu sendiri. Menurut Magill (2011, p. 10), closed skill is when the supporting surface, objek, other poeple involve in the performance of a skill are stationary. Artinya, keterampilan tertutup adalah ketika pendukung baik permukaan, objek, atau orang lain dalam menampilkan keterampilan dalam keadaan diam. Keterampilan tetutup lebih mudah daripada yang terbuka karena dipengaruhi oleh kemampuan individu, sehingga faktor lain di luar gerak tidak mempengaruhi. Jadi, latihan metode drill konstan akan sangat berguna dan diharapkan dengan penggunaan metode ini dapat dilakukan teknik gerakan servis yang efisien dan sempurna. Jika dilihat dari karakteristik metode tersebut, yang menjadi faktor penyebab kurang efektifnya metode ini adalah rasa bosan.

Metode drill arah sasaran berubah-ubah adalah melakukan teknik servis dengan arah sasaran yang berubah-ubah. Artinya, ada variasi latihan dan pengaturan arah sasaran yang tidak tetap. Pelaksanaan latihan dengan sistem random/acak tidak secara berurutan/teratur dalam satu sesi latihan, tetapi lebih menekankan pada variasi beberapa arah sasaran dalam latihan. Berkaitan dengan hal ini, Schmidt \& Lee (2008, p. 249) mengemukakan:

In random practice, for examplethe order of rehearsal of a number of different tasks is intermingled, or mixed, during the practice period. Learners rotate continually among the tasks and, in the most extreme case, they never perform the same task twice in arow.

Kelebihan metode sasaran berubah-ubah adalah adanya peluang untuk pengayaan teknik keterampilan gerak yang dilatihkan. Dalam hal ini adalah drill sasaran berubah ubah, dengan demikian membuat seorang anak akan menampilkan kemampuan terbaiknya dan mempunyai pengembangan teknik variasi dalam melakukan servis dengan penempatan yang baik. Selain itu metode drill sasaran berubah-ubah menuntut atlet untuk lebih trampil (Schmidt \& Lee, 2008, p. 375).

Pembelajaran gerak (motor learning) adalah serangkaian proses yang terkait dengan praktik atau pengalaman yang mengarah kepada keuntungan yang relatif permanen dalam kemampuan untuk kinerja yang terampil. Edwards (2011, p. 9) menyatakan bahwa pembelajaran gerak (motor learning) berkaitan dengan proses yang mendasari akuisisi dan keterampilan kerja motorik.

Jika memperhatikan karakteristik metode latihan drill arah sasaran berubah-ubah juga mempunyai kelebihan dari segi peningkatan kemampuan keterampilan secara koginitif. Dalam hal ini, metode drill sasaran berubah ubah dirancang agar atlet mampu melakukan tugas yang telah diberikan dengan sasaran yang ditentukan. Atlet diharapkan mampu mengukur dan menempatkan bola sesuai dengan keinginan. Anderson (2011, p.274) menyatakan tahap belajar kognitif (cognitive stage) adalah peserta didik berfokus pada masalah-masalah yang berorientasi pada kognitif yang berkaitan dengan apa yang harus dilakukan dan bagaimana melakukannya. Edwards (2011, p. 251) menyebut tahap ini sebagai tahap kognitif karena proses mental yang sadar mendominasi tahap awal pembelajaran. Edwards (2011, p. 251) menambahkan bahwa dalam tahapan ini hampir sepenuhnya peserta didik bergantung pada memori deklaratif dan informasi secara sadar dimanipulasi dan dilatih dalam merumuskan perintah motorik.

Jika dilihat metode sasaran berubah-ubah dan sasaran konstan memang tampak metode sasaran berubah-ubah lebih sedikit mempunyai keunggulan daripada sasaran konstan. Jika diperhatikan metode drill sasaran berubah-ubah lebih aplikatif dalam permainan sebenarnya dan dapat diterapkan pada atlet yang mempunyai koordinasi tinggi. Untuk metode drill arah sasaran konstan jika diterapkan pada atlet yang mempunyai koordinasi rendah akan lebih baik.

Dari uraian tersebut dan dengan memperhatikan segala kelebihan dan kekurangan masing-masing dapat disimpulkan bahwa antara metode latihan drill akan memberikan pengaruh terhadap keterampilan servis backspin tenis meja. Berdasarkan teori dan hasil penelitian drill 
arah konstan lebih cocok untuk koordinasi rendah dan drill arah sasaran yang berubah-ubah lebih cocok pada kelompok atlet yang mempunyai koordinasi tinggi.

Perbedaan Pengaruh antara Koordinasi Tinggi dan Rendah terhadap Ketepatan Servis Backspin

Permainan tenis meja termasuk dalam keterampilan terbuka. Artinya, bahwa kondisi lingkungan tempat bermain sulit diprediksi dan tidak mudah di duga baik kecepatan dan arah. Arah sasaran bola akan dipukul tidak pernah jatuh pada sasaran yang sama, tetapi selalu berubah-ubah. Untuk itu deperlukan suatu keterampilan dan kemampuan untuk mengatur dan melakukan servis dengan arah sasaran yang berubah ubah. Berkaitan dengan hal ini Bompa (2000, p. 43) mengemukakan:

A well-coordinated child will always acquire a skill quickly and be able to perform it smoothly. Compared with a child who might perform a movement with stiffness and difficulty, a well-coordinated young athlete will spend less energy for the same performance. Therefore, good coordination results in more skill effectiveness.

Maksud dari pernyataan Bompa tersebut, anak yang berkoordinasi dengan baik akan selalu memperoleh keahlian dengan cepat dan dapat melakukan dengan lancar, dibandingkan dengan anak yang melakukan gerakan dengan kekakuan dan kesulitan. Seorang atlet muda yang berkoordinasi baik akan menghabiskan energi yang lebih sedikit untuk kinerja yang sama. Oleh karena itu hasil koordinasi yang baik akan lebih efektif di dalam suatu keterampilan.

Berikut menyikapi pernyataan Bompa (2000, p. 43) yang telah dikemukakan, yakni: "anak yang berkoordinasi baik akan selalu memperoleh keahlian cepat dan dapat melakukan keahlian dengan lancar, dibandingkan dengan anak yang mungkin melakukan gerakan dengan kekakuan dan kesulitan." Berdasarkan pendapat Bompa, dapat disimpulkan bahwa, anak yang memiliki tingkat koordinasi rendah akan melakukan gerakan dengan lambat serta kaku, dan dapat mengalami kesulitan pada saat melakukan latihan olahraga, khususnya dalam melakukan keterampilan servis backspin tenis meja pada atlet pemula. Selain lambat dan kaku, kemampuan untuk mengintegrasikan gerakan menjadi sebuah gerakan yang harmonis akan membutuhkan waktu latihan yang lebih lama dibandingkan dengan atlet yang memiliki tingkat koordinasi tinggi.

Interaksi antara Metode Latihan Drill (Konstan dan Berubah-ubah) dan Koordinasi Tinggi dan Rendah terhadap Ketepatan Servis Backspin.

Dari beberapa pembahasan tersebut, apabila didapat atlet tersebut memiliki koordinasi rendah, atlet tersebut lebih cocok dilatih dengan metode drill konstan dan atlet yang memiliki koordinasi tinggi lebih cocok dilatih dengan drill berubah-ubah. Hal ini dikarenakan atlet yang memiliki koordinasi rendah akan lebih terbantu karena drill arah sasaran konstan bersifat tidak menyulitkan atlet arah selama latihan sasarannya tidak berubah ubah sehingga atlet akan terbantu untuk melakukan drill, sedangkan bagi atlet yang memiliki koordinasi tinggi lebih cocok dengan metode drill berubahubah.

Hal ini dikarenakan drill arah sasaran berubah-ubah dalam pelaksanaannya lebih identik dengan suasana atau keadaan dalam bertanding, sehingga bagi atlet yang memiliki koordinasi tinggi akan mudah melakukannya jika dibandingkan bagi atlet yang memiliki koordinasi rendah. Berdasarkan kajian teori dan hasil penelitian dapat disimpulkan bahwa terdapat interkasi antara meode latihan metode drill dan koordinasi terhadap ketepatan servis tenis meja.

Dengan demikian perbedaaan antara drill arah konstan dan drill arah sasaran berubahubah diasumsikan memberikan pengaruh terhadap keterampilan servis atlet pemula. Untuk itu dengan memilih metode dengan tingkat kemampuan koodinasi yang dimiliki.

\section{SIMPULAN, IMPLIKASI, DAN SARAN}

\section{Simpulan}

Berdasarkan hasil penelitian dan hasil analisis data yang telah dilakukan, diperoleh kesimpulan sebagai berikut: (1) terdapat perbedaan pengaruh signifikan antara metode drill arah sasaran konstan dan drill arah sasaran berubah-ubah terhadap ketepatan servis backspin tenis meja atlet pemula, dan metode drill arah sasaran berubah-ubah mempunyai pengaruh lebih tinggi dari metode drill arah sasaran konstan; (2) terdapat perbedaan pengaruh signifikan antara tingkat koordinasi terhadap servis backspin tenis meja, dan koordinasi tinggi mempunyai pengaruh lebih tinggi dari koordinasi rendah; (3) terdapat interaksi antara metode drill 
arah sasaran konstan dan drill arah sasaran berubah-ubah dan koordinasi terhadap ketepatan servis tenis meja atlet pemula. Hasil latihan yang diajarkan dengan metode drill sasaran berubah-ubah dengan koordinasi tinggi mempunyai pengaruh lebih tinggi daripada metode latihan drill konstan koordinasi tinggi. Bagi atlet yang dilatih dengan metode drill sasaran konstan koordinasi rendah mempunyai pengaruh lebih tinggi daripada metode drill sasaran berubah-ubah koordinasi rendah.

\section{Implikasi}

Berdasarkan kesimpulan dalam penelitian ternyata penerapan metode drill yang tepat akan memberikan pengaruh yang signifikan terhadap ketepatan servis backspin atlet pemula. Latihan drill arah sasaran konstan dan drill arah sasaran berubah-ubah serta koordinasi tinggi dan rendah merupakan variabel-variabel yang berpengaruh terhadap ketepatan servis backspin.

Hal ini menunjukkan bahwa setiap variabel memiliki implikasi baik secara bersama-sama maupun sendiri-sendiri. Atas dasar kesimpulan yang telah diambil tersebut, dapat dikemukakan implikasi sebagai berikut.

Kesimpulan dalam penelitian menunjukkan bahwa latihan drill arah sasaran berubahubah ternyata memberikan pengaruh yang lebih baik terhadap hasil ketepatan servis backspin atlet pemula Sleman. Hasil penelitian dapat dipertanggungjawabkan secara ilmiah, oleh karena itu pelatih dan pembina olahraga dapat menerapkan hasil penelitian dalam melatih atletnya serta memanfaatkan sarana dan prasarana yang tersedia.

Memperhatikan kelebihan dan keefektifan dari latihan drill arah sasaran konstan dan drill arah sasaran berubah-ubah, latihan ini dapat digunakan sebagai solusi dan variasi bagi pelatih atau pembina olahraga dalam upaya peningkatan ketepatan servis backspin.

Berkenaan dengan penerapan kedua metode latihan yang dapat digunakan dalam latihan ketepatan servis backspin, masih ada faktor lain yang berpengaruh terhadap hasil ketepatan servis yaitu koordinasi (tinggi dan rendah). Hasil menunjukkan bahwa ada perbedaan peningkatan ketepatan servis backspin yang sangat signifikan antara kelompok yang memiliki koordinasi tinggi dan rendah. Hal ini mengisyaratkan kepada pelatih atau pembina olahraga, bahwa upaya meningkatkan hasil ketepatan servis backspin, hendaknya faktor koordinasi yang dimiliki oleh setiap atlet harus diperhatikan.

Hal ini menunjukkan bahwa suatu metode latihan belum tentu sesuai dengan semua kelompok, oleh karena itu pelatih atau pembina olahraga harus pandai-pandai memilih metode yang tepat dan efektif bagi atlet serta memperhatikan juga variabel atributnya. Hasil penelitian secara praktis dapat digunakan sebagai acuan bagi pelatih atau pembina olahraga untuk dapat memberikan pengalaman yang berharga kepada atlet. Secara aktif dapat memanfaatkan metode latihan drill arah sasaran konstan dan drill arah sasaran berubah-ubah serta koordinasi untuk meningkatkan hasil ketepatan servis backspin pada khususnya dan prestasi olahraga tenis meja pada umumnya.

\section{Saran}

Saran kepada para praktisi olahraga tenis meja. Hasil penelitian yang telah dilakukan membuktikan bahwa secara keseluruhan metode drill arah sasaran berubah-ubah lebih efektif digunakan daripada metode drill arah sasaran konstan. Selain itu, terdapat interaksi antara metode drill dan koordinasi. Bagi kelompok perlakuan yang mempunyai koordinasi tinggi, metode drill arah sasaran berubah-ubah lebih effektif. Metode drill arah sasaran konstan lebih efektif digunakan oleh atlet yang memiliki koordinasi rendah, khususnya untuk metode yang digunakan dalam permainan tenis meja.

Disarankan kepada pelatih tenis meja pemula agar dapat menetukan metode latihan yang sesuai dengan karakteristik dan kemampuan kondisi atlet. Pelatih juga agar lebih memperhatikan kemampuan koordinasi sebagai pendukung seuatu keterampilan motorik anak.

Saran kepada atlet dan orang tua. Berdasarkan hasil penelitian ini, disarankan kepada atlet dan orang tua untuk mendukung dan ikut serta dalam mejalankan proses latihan tidak hanya terfokus pada materi latihan yang telah diberikan oleh pelatih, tetapi ikut serta dalam proses menciptakan suasa latihan yang baik.

Saran kepada peneliti selanjutnya Penelitian ini terbukti bahwa metode drill arah sasaran berubah-ubah mampu meningkatkan keterampilan servis backspin. Hal ini dapat dijadikan informasi secara empirik yang dapat digunakan oleh para pakar dan peneliti di bidang pendidikan jasmai dan olahraga. Untuk atlet pemula disarankan lebih berinovasi dalam perbaikan metode latihan khususnya dalam 
meningkatkat kemampuan motorik dan teknik permainan. Meskipun demikian, peneliti yang bermaksud yang melanjutkan penelitian untuk meyakinkan hasil temuan dan mengembangkan lebih lanjut. Disarankan untuk melakukan pengendalian lebih baik dalam rangkaian proses eksperimen. Pengendalian terhadap variabel bebas di luar variabel yang diteliti agar dilakukan secara cermat dan teliti.

\section{DAFTAR PUSTAKA}

Bompa, T. O. (2000). Total training for young champions. Champaign: Human Kinetics.

Edwards, W. H. (2011). Motor learning and control: From theory to practice. Belmont: Wadsworth Cengage Learning.

Ismaryati. (2011. Tes dan pengukuran dalam olahraga. Surakarta: UNS Press

Katsikadelis, M., Pilianidis, T., \& Mantzoura, N. (2013). The interaction between serves and match winning in table tennis players in the London 2012 Olympic Games. In The 13th ITTF Sports Science Congress. Paris: ITTF Sport Science congress. Retrieved from

http://www.old.ittf.com/ittf_science/SSCen ter/docs/Katsikadelis M_revised (2)OK.pdf

Magill, R. A. (2011). Motor learning and control: Concepts and applications. New York, N.Y.: McGraw-Hill.
Miller, D. K. (David K. (2013). Measurement by the physical educator: why and how (7 edition). New York, United States: McGraw-Hill Education.

Schmidt, R. A., \& Lee, T. D. (2008). Motor learning and performance: from principles to application. New York: Human Kinetics.

Sudjana. (2002). Desain dan analisis eksperimen (Ed. 4). Bandung: Tarsito.

Sugiyono. (2010). Metode penelitian pendidikan: Pendekatan kuantitatif, kualitatif, dan $R \& D$. Bandung: Alfabeta.

The International Table Tennis Federation. (2016). The International Table Tennis Feder: Handbook 2016. Lausanne, Switzerland: The International Table Tennis Federation. Retrieved from http://www.old.ittf.com/ittf_handbook/201 6/2016_ITTF_HB.pdf

Tomoliyus. (2014). Pengembangan instrumen kemampuan ketepatan fore hand, backhand drive dalam permainan tenis meja. Yogyakarta. Retrieved from http://staffnew.uny.ac.id/upload/13112171 7/penelitian/12.+Pengembangan+instrume $\mathrm{n}+$ Ketetapan+Forehand+dan+backhand $+\mathrm{D}$ rive+tenis+mejaNew+Microsoft+Office+ Word+Document+_2_.pdf. 